\title{
Vergence Paresis in Multiple System Atrophy
}

Key words: multiple system atrophy, diplopia, convergence, divergence, midbrain

LEFT

LEFT

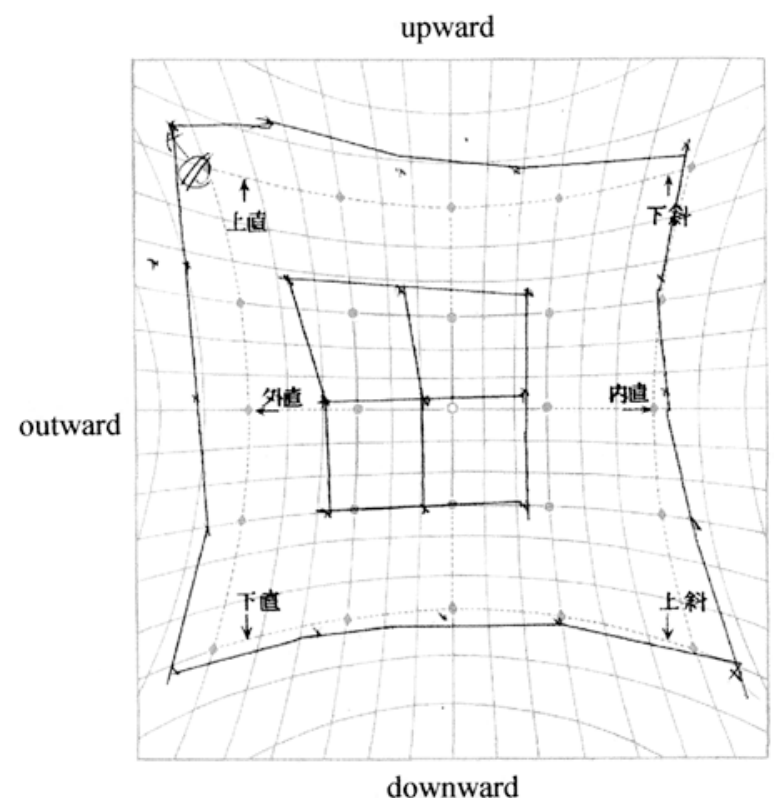

A

downward

upward

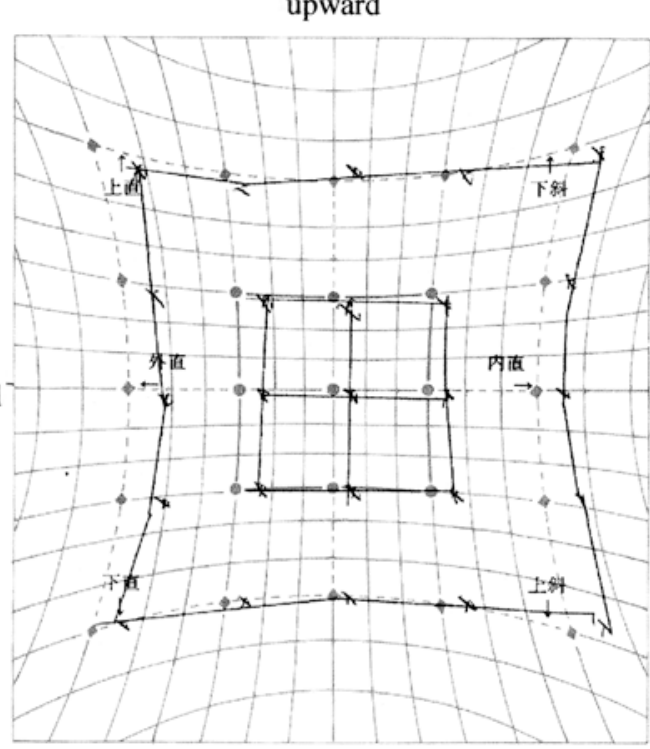

downward

upward

B
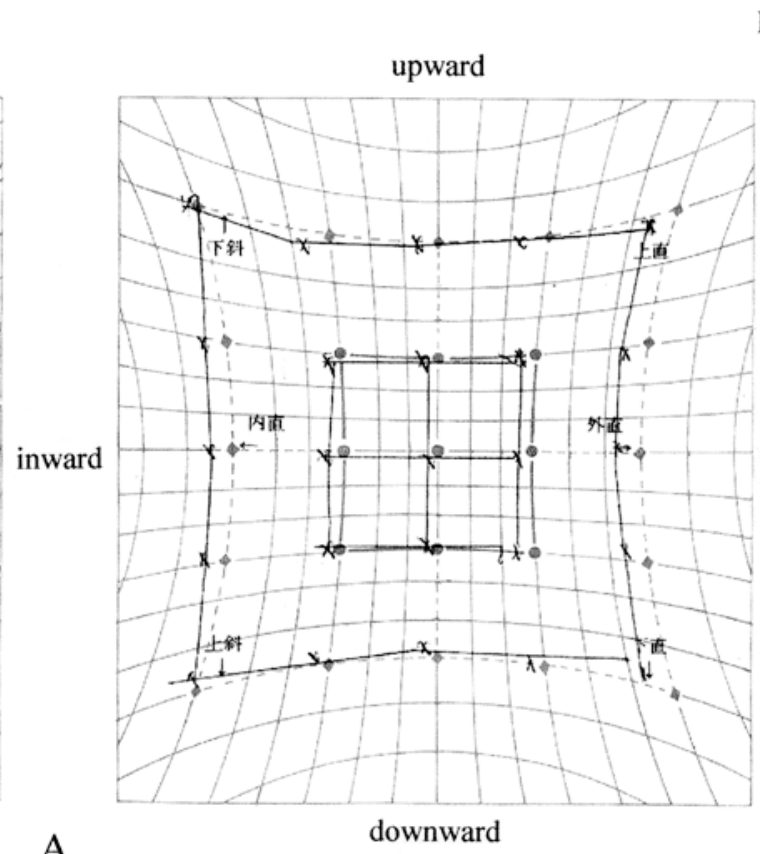

RIGHT

outward

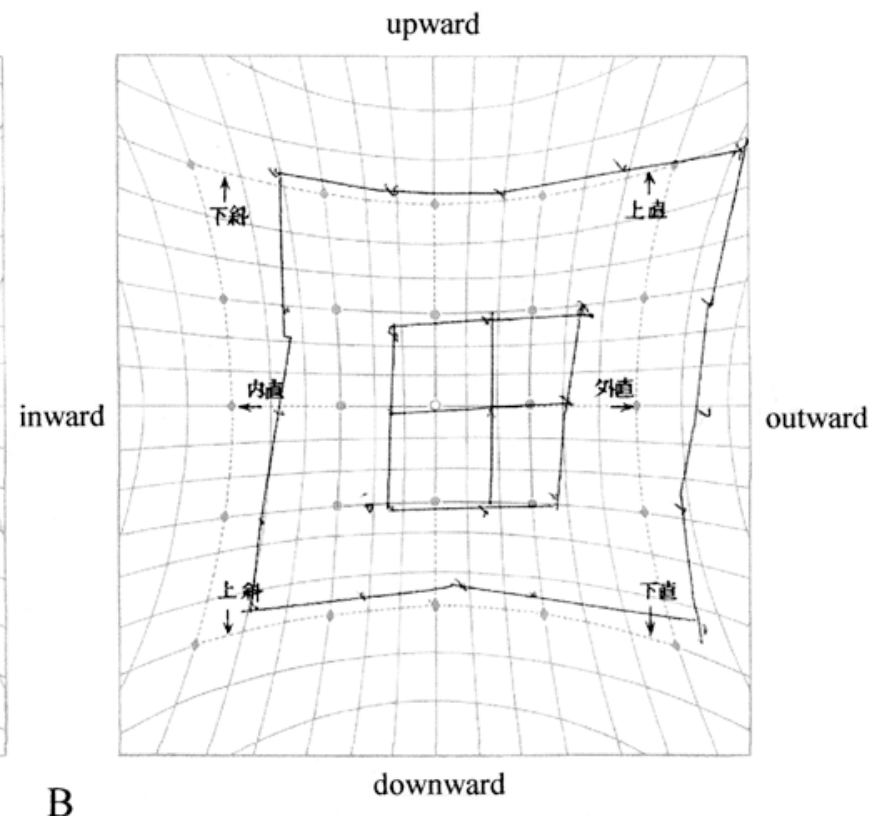

Figure 1. Hess chart of the patients. Hess chart of case 1 (A) showed mild divergence paresis, whereas that of case 2 (B) showed convergence paresis with mild skew. 
Diplopia has not been considered a feature of multiple system atrophy (MSA). However, two of our MSA patients (case 1, 79-year-old man, disease duration 5 years; case 2, 68-year-old man, disease duration 5 years) developed mild horizontal diplopia. Both patients had no eye movement limitation suggestive of abducens palsy etc., except for poor convergence and mild upgaze paresis. Characteristically, the grade of the horizontal diplopia in both patients was unchanged in every direction. On the Hess chart, a paresis of divergence (case 1) and of convergence (case 2) was detected (Fig. 1). Although vergence paresis is uncommon, it is a clinical localizing sign of the midbrain tegmentum $(1,2)$, and is potentially treatable with prism eyeglasses.

\section{References}

1) Ohtsuka K, Maeda S, Oguri N. Accommodation and convergence palsy caused by lesions in the bilateral rostral superior colliculus. Am J Ophthalmol 133: 425-427, 2002.

2) Mays LE, Porter JD, Gamlin PD, Tello CA. Neural control of vergence eye movements: neurons encoding vergence velocity. J Neurophysiol 56: 1007-1021, 1986.

Ryuji SaKakibara, Takashi Ito, Tatsuya Yamamoto, Tomoyuki UchiYama, Zhi LiU and Takamichi HattoRI From Department of Neurology, Chiba University, Chiba

Received for publication March 8, 2005; Accepted for publication March 29, 2005

Reprint requests should be addressed to Dr. Ryuji Sakakibara, Department of Neurology Chiba University, 1-8-1 Inohana Chuo-ku, Chiba 260-8670 